\title{
An in vitro Comparative Evaluation of the Sealing Ability of Mineral Trioxide Aggregate with Different Mixing Reagents
}

${ }^{1}$ Teena Dsouza, ${ }^{2}$ Shreetha Bhandary, ${ }^{3}$ Raghu Srinivasan

\begin{abstract}
Background: Mineral trioxide aggregate (MTA) exhibits several properties of an ideal root-end filling. It, however, has certain disadvantages such as long setting time, difficult handling characteristics, and limited antimicrobial activity. In order to improve its properties, several commonly used reagents have been used instead of sterile water. Hence the objective of this study was to evaluate the root-end sealing ability of white MTA combined with either distilled water, $0.12 \%$ chlorhexidine solution, $10 \%$ doxycycline solution, $3 \%$ sodium hypochlorite solution, or $10 \%$ calcium chloride solution using a bacterial leakage test.
\end{abstract}

Materials and methods: Seventy-two extracted, decoronated human maxillary incisor teeth were used. After cleaning and shaping of the canals, root-end resection was performed at $90^{\circ}$. Root-end cavities were filled with ProRoot MTA combined with the test reagents. Microleakage was assessed using a bacterial leakage test for a period of 60 days. Results were analyzed using the log rank test. The level of significance was 0.05 .

Results: There was a significant increase in the sealing ability when MTA was mixed with calcium chloride, sodium hypochlorite, or doxycycline when compared with distilled water or chlorhexidine. Also, MTA combined with calcium chloride demonstrated a higher probability of surviving 60 days.

Conclusion: The sealing ability of MTA was improved when combined with calcium chloride, sodium hypochlorite, and doxycycline.

Keywords: Bacterial leakage, Calcium chloride, Chlorhexidine, Doxycycline, Enterococcus faecalis, Microleakage, Mineral trioxide aggregate, Root-end filling material, Sodium hypochlorite.

How to cite this article: Dsouza T, Bhandary S, Srinivasan R. An in vitro Comparative Evaluation of the Sealing Ability of Mineral Trioxide Aggregate with Different Mixing Reagents. World J Dent 2016;7(2):54-58.

Source of support: Nil

Conflict of interest: None

\section{INTRODUCTION}

Conventional root canal treatment is a highly successful procedure with a success rate approaching 95\%. In the

${ }^{1}$ Assistant Professor, ${ }^{2,3}$ Professor

${ }^{1}$ Department of Conservative Dentistry and Endodontics, AB Shetty Memorial Institute of Dental Sciences, Mangaluru Karnataka, India

${ }^{2,3}$ Department of Conservative Dentistry and Endodontics AECS, Maaruti Dental College, Bengaluru, Karnataka, India

Corresponding Author: Teena Dsouza, Assistant Professor Department of Conservative Dentistry and Endodontics, AB Shetty Memorial Institute of Dental Sciences, Mangaluru, Karnataka India, Phone: +918242211572, e-mail: tinsha_7@hotmail.com rare instance of failure, nonsurgical retreatment is carried out. However, when nonsurgical root canal treatment fails or is inadvisable, treatment by a surgical approach is indicated to obtain a good apical seal and resolve persistent infections. ${ }^{1,2}$ Surgical endodontic treatment usually consists of apical resection, root-end cavity preparation followed by a retrofilling to seal the communication between the root canal and the periradicular tissues. ${ }^{1}$ Root-end filling materials should ideally be nontoxic, biocompatible, nonresorbable, and dimensionally stable. ${ }^{3}$ A variety of materials have been suggested and used previously as root-end filling materials. ${ }^{1}$ Unfortunately, none of these materials have been found to fulfill the ideal characteristics of a root-end filling material. ${ }^{4}$

The quest for an ideal retrograde filling material led to the development of mineral trioxide aggregate (MTA) in $1993.5,6$ It is a bioactive material that promotes hard tissue deposition and exhibits excellent biocompatibility, superior sealing ability, and marginal adaptation. More importantly, it is tolerant to the presence of moisture, an important requirement for a root-end filling material. ${ }^{7}$ Despite the favorable clinical properties of MTA, drawbacks do exist. It has a prolonged setting time, difficult handling characteristics, and limited antimicrobial activity. ${ }^{8}$ A long setting time of 2 hours 45 minutes may increase its solubility and lead to disintegration, subsequently causing leakage. ${ }^{9}$

In order to overcome these limitations, various additives such as calcium chloride, calcium formate, sodium phosphate dibasic, sodium hypochlorite gel, and $\mathrm{K}-\mathrm{Y}$ jelly are used, which have been found to accelerate the setting of MTA and improve its working properties. ${ }^{10}$ Chlorhexidine and doxycycline have been used with MTA to improve their antimicrobial activity. ${ }^{11}$

Mixing MTA with a variety of agents has shown to yield superior physical properties, biocompatibility, dimensional stability, and antimicrobial properties in various studies. ${ }^{6,8-10}$ However, the most important factor determining the success of an endodontic repair material is the sealing ability. Hence, the objective of this study was to evaluate the root-end sealing ability of MTA (white ProRoot MTA, Dentsply) combined with either distilled water, $0.12 \%$ chlorhexidine solution, $10 \%$ doxycycline solution, $3 \%$ sodium hypochlorite solution, or $10 \%$ calcium chloride solution using a bacterial leakage test. 


\section{MATERIALS AND METHODS}

\section{Sample Selection}

Seventy-two extracted human single-rooted maxillary incisor teeth extracted for periodontal reasons were used in the study.

\section{Preparation of Teeth}

All teeth were stored in $0.9 \%$ sodium chloride solution to avoid dehydration. The teeth were decoronated using a safe-sided diamond disk (Horico, Germany) to create a standardized root length of $16 \mathrm{~mm}$. Cleaning and shaping of canals was performed using ProTaper rotary files (Dentsply, Maillefer, Switzerland) until size F4. Irrigation was done with $5 \mathrm{ml}$ of $5.25 \%$ sodium hypochlorite solution and rinsed with $3 \mathrm{ml}$ of $17 \%$ EDTA to remove the smear layer. Canals were then dried with sterile paper points. The roots were stored at $37^{\circ} \mathrm{C}$ and $100 \%$ relative humidity for 48 hours.

\section{Root-end Resection and Cavity Preparation}

The apical resection was made at $90^{\circ}$ angulation to the longitudinal axis of each tooth, $3 \mathrm{~mm}$ away from the root apex with a diamond fissure bur ISO\#10 (Horico, Germany) under continuous water and air spray. Rootend cavities of $3 \mathrm{~mm}$ were prepared using an ultrasonic retrotip (Obtura Spartan, USA) with an ultrasonic handpiece (EMS Piezon system, Switzerland).

Following apical preparation, teeth were randomly divided into five experimental groups and one control group $(\mathrm{n}=12$ each) according to the root-end filling material.

\section{Experimental Groups}

Group 1: Mineral trioxide aggregate $(0.12 \mathrm{gm})$ mixed with $90 \mu \mathrm{l}$ of distilled water.

Group 2: Mineral trioxide aggregate ( $0.12 \mathrm{gm})$ mixed with $90 \mu \mathrm{l}$ of $0.12 \%$ chlorhexidine solution.

Group 3: Mineral trioxide aggregate $(0.12 \mathrm{gm})$ mixed with $90 \mu \mathrm{l}$ of $10 \%$ doxycycline solution.

Group 4: Mineral trioxide aggregate $(0.12 \mathrm{gm})$ mixed with $90 \mu \mathrm{l}$ of $3 \%$ sodium hypochlorite solution.

Group 5: Mineral trioxide aggregate $(0.12 \mathrm{gm})$ mixed with $90 \mu \mathrm{l}$ of $10 \%$ calcium chloride solution.

Control group: Teeth did not receive any root-end filling material.

\section{Root-end Filling}

The retrocavities were filled according to the groups as listed above using an MTA carrier (GDC Marketing, India) and condensed using an amalgam condenser, after which the excess material was removed with a sterile cotton pellet.
All the experimental and control groups were covered with two layers of nail varnish except for the apical and coronal surfaces. The root ends were wrapped in a sterile moist gauze for 3 hours to allow the root-end filling material to set. All teeth were then kept in an incubator at $37^{\circ} \mathrm{C}$ for 48 hours. $^{10}$

\section{Apical Microleakage}

To assess the apical microleakage, a bacterial leakage test was performed. Eppendorf tubes equipped with microcaps were used to suspend the prepared teeth in a brain-heart infusion (BHI) broth. An opening was made through the center of each cap and the tooth was placed into the opening such that $3 \mathrm{~mm}$ of the root apex was immersed in the broth. The gap between the tooth and the opening was filled with sticky wax. Aluminum foil was placed over the apparatus to protect against air contaminants entering the canal during prolonged incubation. The completed apparatus was then sterilized by autoclaving at $15 \mathrm{lbs}$ pressure for 20 minutes. A 24-hour broth culture of Enterococcus faecalis (ATCC 29212 strain) was placed in the coronal part of the canal. The tubes were incubated at $37^{\circ} \mathrm{C}$ until the $\mathrm{BHI}$ broth became turbid, indicating bacterial growth. Fresh overnight cultures of E. faecalis organism were added to the tubes at 2-day intervals. Once turbidity was detected, the sample was removed from the incubator and the day of leakage was recorded. The turbidity of the broth was recorded daily for a period of 60 days. ${ }^{11}$

\section{Statistical Analysis}

A statistical analysis of data was performed with the log rank test using the Statistical Package for the Social Sciences (SPSS) 15 software data-analyzing software.

\section{RESULTS}

At the end of 60 days, groups III, IV, and V showed leakage in three samples, group II in four samples, and group I in eight samples. All samples in the positive control group showed turbidity of the broth within 48 hours.

At the end of 30 days, three samples in group I leaked. At the end of 45 days, three samples in group I, four samples in group II, and three samples in group IV leaked. At the end of 60 days, two samples in group I, three samples in group III, and three samples in group V showed leakage. Descriptive statistics have been presented in Table 1.

The pairwise log rank test was done to check the pairwise equality of "time to leakage" among every pair of groups (Table 2).

Results of pairwise log rank test showed that with respect to time to leakage, group I (MTA + distilled water) 
Table 1: Descriptive statistics

\begin{tabular}{|c|c|c|c|c|}
\hline \multirow[b]{3}{*}{ Groups } & \multicolumn{4}{|c|}{ Mean time to leakage } \\
\hline & \multirow[b]{2}{*}{ Estimate } & \multirow[b]{2}{*}{$\begin{array}{l}\text { Std. } \\
\text { error }\end{array}$} & \multicolumn{2}{|c|}{$\begin{array}{l}\text { 95\% Confidence } \\
\text { interval }\end{array}$} \\
\hline & & & $\begin{array}{l}\text { Lower } \\
\text { bound }\end{array}$ & $\begin{array}{l}\text { Upper } \\
\text { bound }\end{array}$ \\
\hline $\begin{array}{l}\text { Mineral trioxide aggregate } \\
\text { (MTA) + distilled water }\end{array}$ & 42.583 & 4.496 & 33.771 & 51.396 \\
\hline MTA $+0.12 \%$ chlorhexidine & 53.500 & 2.886 & 47.844 & 59.156 \\
\hline MTA $+10 \%$ doxycycline & 57.667 & 1.391 & 54.940 & 60.393 \\
\hline $\begin{array}{l}\text { MTA }+3 \% \text { sodium } \\
\text { hypochlorite }\end{array}$ & 54.667 & 2.699 & 49.377 & 59.956 \\
\hline $\begin{array}{l}\text { MTA }+10 \% \text { calcium } \\
\text { chloride }\end{array}$ & 58.250 & 1.430 & 55.448 & 61.052 \\
\hline Positive controls & 2.000 & .000 & 2.000 & 2.000 \\
\hline Overall & 44.778 & 2.597 & 39.687 & 49.868 \\
\hline
\end{tabular}

was significantly different from the other groups, except group II (MTA $+0.12 \%$ chlorhexidine). No statistically significant difference was found between groups I and II. The level of significance is considered to be $5 \%$.

The Kaplan-Meier survival analysis showed that the probability of surviving 60 days in group V (MTA $+10 \%$ calcium chloride) was significantly higher when compared with the other groups (Graph 1).

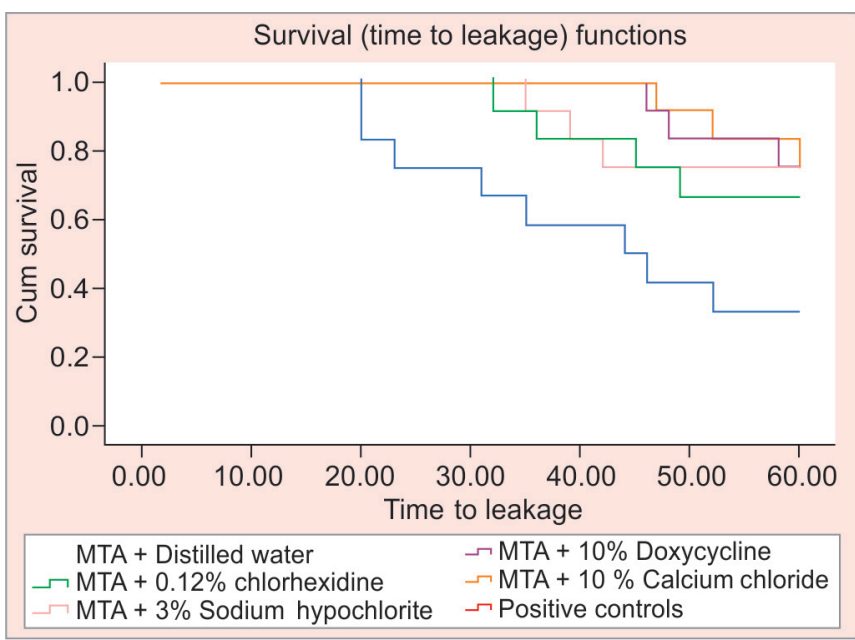

Graph 1: Kaplan-Meier curve to estimate the survival up to leakage

\section{DISCUSSION}

Mineral trioxide aggregate has been considered as the "gold standard" for use in apical surgery. ${ }^{1}$ It has been proven to possess a superior apical sealing capacity in numerous studies when compared to other root-end filling materials. ${ }^{11}$ However, its prolonged setting time can compromise its sealing ability and cause leakage during the initial setting phase. ${ }^{12}$

Our study was designed to compare the root-end sealing ability of MTA when mixed with calcium chloride, sodium hypochlorite, chlorhexidine, and doxycycline. Distilled water was used as control. The sealing ability of these materials was assessed by evaluating the apical microleakage recorded over a period of 60 days.

Apical microleakage of MTA has been assessed by using methods such as dye penetration, fluid filtration, or bacterial infiltration leakage methods. ${ }^{4}$ According to Timpawat et al, assessing leakage with the use of bacteria can be clinically and biologically more relevant than the other methods. Bacteria used as tracers most closely simulate a clinical scenario in terms of leakage. ${ }^{13}$ Hence, in the present study, a bacterial leakage model with $E$. faecalis as a tracer was used.

The various reagents used in our study to be mixed with MTA included calcium chloride, sodium hypochlorite, chlorhexidine, and doxycycline. Kogan et $\mathrm{al}^{8}$ demonstrated that the addition of sodium hypochlorite, K-Y jelly, and calcium chloride decreased the setting time of MTA to 20 to 25 minutes. In an attempt to enhance the setting and handling properties, AlAnezi et al suggested sodium hypochlorite, K-Y jelly, and calcium chloride to be used with MTA and proved them to be possible substitutes to distilled water. In endodontic apical surgery, a short setting time is desired to prevent the washout of the material. Thus, the use of these accelerants brings about an early setting of MTA and, hence, significantly increases the sealing ability. ${ }^{14}$

Chlorhexidine and doxycycline have been known to possess antimicrobial property and substantivity. ${ }^{11}$ Srikumar and Shetty ${ }^{15}$ demonstrated that irrigation

Table 2: Pairwise log rank test to check the pairwise equality of "time to leakage"

\begin{tabular}{|c|c|c|c|c|c|c|c|c|c|c|}
\hline \multirow[b]{2}{*}{ Groups } & \multicolumn{2}{|c|}{$\begin{array}{l}\text { MTA + distilled } \\
\text { water }\end{array}$} & \multicolumn{2}{|c|}{$\begin{array}{l}\text { MTA }+0.12 \% \\
\text { chlorhexidine }\end{array}$} & $\begin{array}{l}\text { MTA } \\
\text { sodi } \\
\text { hypc }\end{array}$ & $\begin{array}{l}3 \% \\
m \\
\text { hlorite }\end{array}$ & \multicolumn{2}{|c|}{$\begin{array}{l}\text { MTA }+10 \% \\
\text { doxycycline }\end{array}$} & \multicolumn{2}{|c|}{$\begin{array}{l}\text { MTA }+10 \% \\
\text { calcium chloride }\end{array}$} \\
\hline & $\begin{array}{l}\text { Chi- } \\
\text { square }\end{array}$ & $p$-value & $\begin{array}{l}\text { Chi- } \\
\text { square }\end{array}$ & $p$-value & $\begin{array}{l}\text { Chi- } \\
\text { square }\end{array}$ & $p$-value & $\begin{array}{l}\text { Chi- } \\
\text { square }\end{array}$ & $p$-value & $\begin{array}{l}\text { Chi- } \\
\text { square }\end{array}$ & $p$-value \\
\hline $\begin{array}{l}\text { Mineral trioxide aggregate } \\
(\mathrm{MTA})+0.12 \% \text { chlorhexidine }\end{array}$ & 3.085 & 0.079 & & & & & & & & \\
\hline MTA $+3 \%$ sodium hypochlorite & 4.209 & 0.040 & 0.154 & 0.695 & & & & & & \\
\hline MTA $+10 \%$ doxycycline & 5.618 & 0.018 & 0.342 & 0.559 & 0.031 & 0.860 & & & & \\
\hline MTA $+10 \%$ calcium chloride & 5.857 & 0.016 & 0.392 & 0.532 & 0.031 & 0.860 & 0.003 & 0.953 & & \\
\hline Positive controls & 23.000 & $<0.001$ & 23.000 & $<0.001$ & 23.000 & $<0.001$ & 23.000 & $<0.001$ & 23.000 & $<0.001$ \\
\hline
\end{tabular}


of the apical cavities with doxycycline hydrochloride significantly improved the apical seal of retrograde filling materials.

Regarding chlorhexidine, some studies have demonstrated a superior antimicrobial activity with MTA/ chlorhexidine when compared with MTA/distilled water mixture. ${ }^{16-19}$ Shahi et $\mathrm{al}^{2}$ and Arruda et $\mathrm{al}^{11}$ have found no significant differences in the sealing ability of MTA when mixed with either distilled water or chlorhexidine, thus suggesting that chlorhexidine was a suitable alternative to replace water. But one study by Kogan et $\mathrm{l}^{8}$ showed that MTA/chlorhexidine had an extended setting time than MTA/distilled water. However, considering the inherent antimicrobial property and a satisfactory sealing ability, we decided to include chlorhexidine as a reagent to be mixed with MTA in our study.

In the present study, MTA combined with calcium chloride, sodium hypochlorite, and doxycycline showed a significant increase in the sealing ability when compared with MTA mixed with distilled water, which was used as control. However, there was no significant difference in the sealing ability between chlorhexidine and distilled water. Also, the probability of surviving 60 days in MTA mixed with $10 \%$ calcium chloride group was significantly higher when compared with the other groups. Analysis of these results suggest a superior sealing ability of MTA/calcium chloride group with respect to the time to leakage. The results of our study are in accordance with those of Hong et al and Bortoluzzi et al wherein MTA-calcium chloride and MTA-sodium hypochlorite displayed lower leakage rate within the given time period. ${ }^{7,20}$ This could be attributed to the acceleration of the setting time of these mixtures.

Mineral trioxide aggregate mixed with chlorhexidine was not statistically significantly different from MTA mixed with distilled water, with similar performances by both, with respect to the time to leakage. Our results are in agreement with those of Shahi et $\mathrm{al}^{2}$ and Arruda et $\mathrm{al}_{1}^{11}$ who showed that there were no significant differences in the sealing ability of white and gray MTA mixed with distilled water and $0.12 \%$ chlorhexidine gluconate when used as root-end filling materials. Kogan et $\mathrm{al}^{8}$ found that MTA mixed with chlorhexidine did not set even at the end of the observational period, i.e., 7 days. The delay in setting of the mixture could be the reason why the BHI broth turned turbid very early in the study period.

Regarding the role of doxycycline, one study by Arruda et $\mathrm{al}^{11}$ showed that replacement of distilled water with doxycycline and chlorhexidine did not alter the sealing properties of MTA Bio. However, the current study demonstrated an increase in the sealing ability with MTA/doxycycline. A probable explanation for the effective sealing could be related to the antibacterial property of this material.

\section{CONCLUSION}

The following conclusions can be drawn from this study:

- Mixing MTA with calcium chloride, sodium hypochlorite, or doxycycline improves the sealing ability when compared with distilled water or chlorhexidine. This difference is statistically significant.

- The probability of the seal surviving 60 days was highest when MTA was mixed with calcium chloride.

- Within the limitations of our study, it can be stated that calcium chloride, sodium hypochlorite, and doxycycline are viable alternatives to distilled water or chlorhexidine for mixing with MTA.

\section{REFERENCES}

1. Poggio C, Lombardini M, Alessandro C, Simonetta R. Solubility of root-end filling materials: a comparative study. J Endod 2007 Sep;33(9):1094-1097.

2. Shahi S, Rahimi S, Yavari HR, Shakouie S, Nezafati S, Abdolrahimi M. Sealing ability of white and gray mineral trioxide aggregate mixed with distilled water and $0.12 \%$ chlorhexidine gluconate when used as root-end filling materials. J Endod 2007 Dec;33(12):1429-1432.

3. Vasudev SK, Goel BR, Tyagi S. Root end filling materials - a review. Endodontology 2003; 15:12-18.

4. Roberts HW, Toth JM, Berzins DW, Charlton DG. Mineral trioxide aggregate material use in endodontic treatment: a review of the literature. Dent Mater 2008 Feb;24(2):149-164.

5. Sonarkar S, Purba R. Bioactive materials in conservative dentistry. Int J Contemp Dent Med Rev 2015; vol 2015: Article ID: 340115.

6. Bidar M, Naderinasab M, Talati A, Ghazvini K, Asgari S, Hadizadeh B, Gharechahi M, Mashadi NA. The effects of different concentrations of chlorhexidine gluconate on the antimicrobial properties of Mineral Trioxide Aggregate and Calcium enrich mixture. Dent Res J 2012 Jul;9(4):466-471.

7. Bortoluzzi EA, Broon NJ, Bramante CM, Garcia RB, Moraes IG, Bernardineli N. Sealing ability of MTA and radiopaque Portland cement with or without calcium chloride for rootend filling. J Endod 2006 Sep;32(9):897-900.

8. Kogan P, He J, Glickman GN, Watanabe I. The effects of various additives on setting properties of MTA. J Endod 2006 Jun;32(6):569-572.

9. Bortoluzzi EA, Broon NJ, Bramante CM, Felippe WT, Filho MT, Esberard RM. The influence of calcium chloride on the setting time, solubility, disintegration and $\mathrm{pH}$ of mineral trioxide aggregate and white Portland cement with a radiopacifier. J Endod 2009 Apr;35(4):550-554.

10. Jafarnia B, Jiang J, He J, Wang Y, Safavi KE, Zhu Q. Evaluation of cytotoxicity of MTA employing various additives. Oral Surg Oral Med Oral Pathol Oral Radiol Endod 2009 May;107(5): 739-744.

11. Arruda RA, Cunha RS, Miguita KB, Silveira CF, De Martin AS, Pinheiro SL, Rocha DG, Bueno CE. Sealing ability of 
mineral trioxide aggregate (MTA) combined with distilled water, chlorhexidine and doxycycline. J Oral Sci 2012 Sep; 54(3):233-239.

12. Hong ST, Bae KS, Baek SH, Kum KY, Lee W. Microleakage of accelerated mineral trioxide aggregate and Portland cement in an in vitro apexification model. J Endod 2008 Jan;34(1): 56-58.

13. Verissimo DM, Vale MS. Methodologies for assessment of apical and coronal leakage of endodontic filling materials: a critical review. J Oral Sci 2006 Sep;48(3):93-98.

14. AlAnezi AZ, Zhu Q, Wang YH, Safavi KE, Jiang J. Effect of selected accelerants on setting time and biocompatibility of Mineral Trioxide Aggregate (MTA). Oral Surg Oral Med Oral Pathol Oral Radiol Endod 2011 Jan;111(1):122-127.

15. Srikumar GP, Shetty KH. Effect of doxycycline on the apical seal of the retrograde filling materials: an ex-vivo study. Endodontology 2012 Dec;24(2):65-70.

16. Stowe TJ, Sedgley CM, Stowe B, Fenno JC. The effects of Chlorhexidine Gluconate $(0.12 \%)$ on the antimicrobial properties of tooth-colored ProRoot mineral trioxide aggregate. J Endod 2004 Jun;30(6):429-431.

17. Holt DM, Watts JD, Beeson TJ, Kirkpatrick TC, Rutledge RE. The anti-microbial effect against Enterococcus faecalis and the compressive strength of two types of mineral trioxide aggregate mixed with sterile water or $2 \%$ chlorhexidine liquid. J Endod 2007 Jul;33(7):844-847.

18. Ankita K, Karthik J, Roopa RN, Arpit J. Sealing ability of mineral trioxide aggregate and biodentine as root end filling material, using two different retro preparation techniques an in vitro study. Int J Contemp Dent Med Rev 2015; vol. 2015, Article ID: 150115.

19. Amitabha C. Will Portland cement be a cheaper alternative to mineral trioxide aggregate in clinical use?: A comprehensive review of literature. Int J Contemp Dent Med Rev 2015; vol. 2015, Article ID: 110215.

20. Mohammadi Z. Sealing ability of MTA cements as orthograde root filling materials. Pesq Bras Odontoped Clin Integr 2008 Sep;8(3):267-270. 